\title{
BMJ Open Factors associated with mobile phone usage to access maternal and child healthcare among women of urban slums in Dhaka, Bangladesh: a cross- sectional study
}

\author{
Sabuj Kanti Mistry (D) , ${ }^{1,2}$ Fahmida Akter, ${ }^{1}$ Uday Narayan Yadav (D) , ${ }^{2,3}$ \\ Md Belal Hossain (D) , ${ }^{1,4}$ Amarynth Sichel, ${ }^{5}$ Alain B Labrique, ${ }^{6}$ \\ Daniel M L Storisteanu ${ }^{7}$
}

To cite: Mistry SK, Akter F, Yadav UN, et al. Factors associated with mobile phone usage to access maternal and child healthcare among women of urban slums in Dhaka, Bangladesh: a crosssectional study. BMJ Open 2021;11:e043933. doi:10.1136/ bmjopen-2020-043933

- Prepublication history and additional material for this paper are available online. To view these files, please visit the journal online (http://dx.doi org/10.1136/bmjopen-2020043933).

Received 20 August 2020 Revised 20 March 2021 Accepted 22 March 2021

Check for updates

(c) Author(s) (or their employer(s)) 2021. Re-use permitted under CC BY-NC. No commercial re-use. See rights and permissions. Published by BMJ.

For numbered affiliations see end of article.

Correspondence to Mr Sabuj Kanti Mistry; smitra411@gmail.com

\section{ABSTRACT}

Introduction With the acute shortage of human resources and infrastructure, mobile phones can be a critical tool for accessing health services and strengthening health systems in Bangladesh. Yet, there is a scarcity of evidence on the use of mobile phones in this context for accessing health services. In this study, we sought to explore the current use of mobile phones for accessing maternal and child healthcare and its determinants among recently delivered women in urban slums of Bangladesh.

Methods The data were collected through interviewing 800 recently delivered women from eight slums of Dhaka city of Bangladesh during May and June 2018. The study followed a cross-sectional design and a two-stage cluster random sampling procedure was followed. A pretested structured questionnaire was employed to collect information. Chi square tests were performed for descriptive analyses and a multilevel binary logistic regression model was executed to explore the determinants of mobile phone usage for accessing maternal and childcare among the participants. Results Overall, $73.8 \%$ of study participants used mobile phones for accessing maternal and child healthcare. After adjusting for potential confounders, participants' age, husband's occupation, sex of household head, women's ownership of mobile phones and household wealth status were found to be significantly associated with higher odds of using mobile phones to access maternal and child healthcare.

Conclusion The study highlighted the possibility of implementing large-scale mobile health (mHealth) interventions in slum settlements for accessing maternal and child healthcare and is a sustainable mitigation strategy for the acute health worker crisis in Bangladesh. The findings of this study are particularly crucial for policymakers and practitioners while they revise the health policy to incorporate mHealth interventions as highlighted in the recently initiated Digital Health Strategy of Bangladesh.

\section{BACKGROUND}

Despite critical shortages in the health workforce, Bangladesh has achieved considerable
Strengths and limitations of this study

- The study focused on the urban slum dwellers, a particularly vulnerable and growing population group.

- The study follows a multistage cluster random sampling procedure which is the preferred method of sampling from a geographically dispersed population group.

- The findings of the study may not be generalisable for the entire slum population as the study area only included the BRAC Manoshicatchment areas.

- As the study was cross-sectional in nature, no temporal relationship can be established.

- The information presented in the study is selfreported and relied on participants' recall, therefore is subjected to recall bias.

progress in health outcomes, particularly towards the reduction of maternal and child mortality. ${ }^{2}$ The maternal mortality ratio (MMR) has declined from 322 deaths per 100000 live births during 1998-2001 to 194 per live births during 2007-2010, with a $5.6 \%$ annual rate of reduction. ${ }^{3}$ Bangladesh achieved the UN Millennium Development Goal 5 target of reducing the maternal mortality ratio by three-quarters between 1990 and 2015 and is signatory of the Sustainable Development Goals (SDGs). ${ }^{4}$ Although there has been a substantial reduction in MMR rates, at the current trajectory it is unlikely that the country will meet SDG targets. Recent data suggest that MMR improvements have stalled. According to the most recent Bangladesh Maternal Mortality and Health Care Survey (BMMS), the MMR was 196 deaths per 100000 live births in Bangladesh, far from the 70 per 100000 live births SDG 
target. BMMS 2016 also reports that nearly one-fourth of pregnant women did not receive a single antenatal care (ANC) visit from any healthcare provider during their entire pregnancy period, and one-third did not receive any postnatal check-up. ${ }^{5}$ At 46 per thousand live births, the mortality rate among children under 5 years is also high in Bangladesh. ${ }^{6}$

The situation is considerably worse in the urban slums of Bangladesh, with a reported under-5 child mortality rate of 57 per 1000 live births compared with the national rate of 46 per 1000 live births. ${ }^{67}$ This is especially critical as the majority of urban growth is occurring in the urban slums of Bangladesh, ${ }^{8}$ and nearly 29 million people, comprising about $55 \%$ of the entire urban population of Bangladesh, reside in urban slums. ${ }^{9}$ The adverse living conditions of urban slums and the lack of accessibility to healthcare facilities and antenatal, delivery and postnatal care services are contributory factors behind poor maternal and child health outcomes. ${ }^{70}$ Research has highlighted the importance of making maternal and child healthcare services accessible to vulnerable people in order to reduce maternal and child morbidity and mortality in slum settlements. ${ }^{11} 12$

Health service delivery, including access to maternal and child care, is seriously compromised in Bangladesh due to an acute shortage of human resources in the healthcare system. ${ }^{1314}$ The Bangladesh health system suffers an extreme shortage of physicians, nurses, midwives and paramedics. ${ }^{15}$ The WHO has recommended a minimum threshold of 4.45 doctors, nurses and midwives per 1000 population to meet the SDGs. ${ }^{16}$ In fact, there are only 3 physicians and 2 nurses per 10000 people in Bangladesh, making it very difficult to provide adequate and timely consultations to patients. ${ }^{17}$ This ratio is especially low in rural areas ( 1 in 15 000), although the urban statistic of 1 doctor per 1500 people also falls far below WHO recommendations. ${ }^{18}$ It is unlikely that this will improve soon given the size of the health workforce in training relative to the total population of the country. Therefore, it is critical to consider mitigation strategies and alternatives that can increase access to health services, particularly for vulnerable populations such as slum dwellers.

Mobile phones have been increasingly recognised as critical tools for strengthening health systems in developing countries and are now applied across the healthcare continuum. ${ }^{19}$ Mobile phones can be used to improve reproductive, maternal, newborn and child health (RMNCH) outcomes through their use of behaviour change communication (BCC), electronic health records and resource management. The ubiquity of mobile phones, characterised by an increasing smartphone ownership in developing countries, can further enable innovations such as point-of-care diagnostics and the use of biometrics to improve resource distribution, enhance continuity of care and increase access of patients to critical services. For example, fingerprint biometrics integrated with smartphones used by health workers facilitated linking patients with a consistent health record and improved continuity of care and RMNCH health outcomes. ${ }^{20}{ }^{21}$ Smartphones can be used for spectrometry and other techniques by the healthcare providers that enable low-cost point-of-care diagnoses of infectious disease. ${ }^{21}$ Using mobile phones can be a useful and costeffective approach to deliver quality healthcare and can help mitigate the overwhelming health worker crisis in Bangladesh. ${ }^{22}$

Many health system processes in Bangladesh and neighbouring low/middle-income countries (LMICs) are based on decades (if not centuries) old domiciliary visit-based template, where community-based health workers or volunteers go home to home in every urban slum and village providing doorstep services to citizens. Given the massive documented global health workforce shortage, this approach is extremely inefficient and timeconsuming, as large amounts of travel time is consumed moving from community to community. Households where clients are not present are often visited, taking up time that might have been better used in patient encounters. Call centres that offer a combination of push-andpull services move us closer toward a patient-centred healthcare system, offering services and advice to clients at their convenience, but also reaching out to patients where they are. Finally, there is a dearth of qualified clinicians who are willing to serve in rural communities for lengthy periods-a problem overcome in the digital paradigm where call centres can be located in urban centres. This mobile health (mHealth) approach can be very effective in the urban slum context where people have limited access to fundamental health services, in part due to distances from formal health facilities and poor living conditions. ${ }^{102}$ It can however be challenging for health services to implement mHealth initiative in resource-poor setting due to lack of access to mobile phones, ${ }^{24}$ thereby slowing progress towards attaining the SDGs. ${ }^{25}$ Yet, the application of mobile phones may be a promising route towards revolutionising healthcare in developing countries like Bangladesh. ${ }^{22}{ }^{26}$ Mobile phones can enhance the efficiency and continuity of care during the antenatal and postnatal period, thereby improving the accessibility and delivery of maternal and child healthcare among women. ${ }^{27}$ This approach was, in fact, recommended by the WHO in its 2019 recommendations on digital health interventions for health system strengthening. ${ }^{28}$ However, there is a scarcity of literature on the use of mobile technology in augmenting healthcare access in Bangladesh, particularly in maternal and child health. ${ }^{22}$

As part of a wider study on the perception and use of technologies such as mobile phones and fingerprint biometrics in healthcare, this study was carried out to investigate the current practices of mobile phone use for accessing maternal and child healthcare by women from urban slums of Dhaka where BRAC, the largest NGO in the world, has been operating its Manoshi intervention since 2007. BRAC's Manoshi intervention covers 6.9 million urban slum dwellers in 10 cities of Bangladesh and is being implemented through its frontline community 
health workers, Shasthya Shebika (SS) and Shasthya Kormi $(S K)$. These healthcare workers provide maternal and childcare services and enable smooth referrals for maternal and childcare-related complications. Several delivery centres are also established in Manoshi slums to promote safe delivery practices. The study also assesses the factors associated with the use of mobile phones for accessing maternal and child healthcare among women in selected slums.

\section{METHODOLOGY}

\section{Study design and participants}

The study followed a cross-sectional design and was carried out between May and June 2018. The study participants were married women who gave birth within the 12 months preceding the survey. By considering 50\% prevalence of usage of mobile phone for maternal and child healthcare services with a 5\% margin of error, $95 \%$ level of confidence and $80 \%$ power of the test, the study required 778 participants which was rounded to $800 .{ }^{29} 30$ To achieve this sample size, we had to approach a total of 882 participants from the selected slums, thus the overall response rate was $91 \%$. A multistage cluster random sampling approach was employed to select study participants from eight randomly selected urban slums of Dhaka city. In the first stage, 8 slums were randomly selected from the 12 slums of Dhaka (using computer-generated algorithm), Bangladesh where BRAC has been operating its Manoshi intervention. In the second stage of sampling, from the list of the eligible women, 100 participants were randomly selected using computer-generated algorithm from each of the slums, making a final sample size of 800 .

\section{BRAC's Manoshi intervention}

Manoshi, which is an acronym of the words for mother, newborn and child in Bengali, is BRAC's RMNCH project, and has been in operation in selected urban slums across Bangladesh since 2007. Manoshi consists of a communitybased essential healthcare package aimed at reducing morbidity and mortality among mothers, newborns and children. The intervention aims to create demand for maternal and child healthcare services through BCC and aims to increase access to emergency obstetric care (EmOC) services through promoting effective referral linkages. BRAC's frontline community health workers, $S S$ s and SKs, deliver BCC interventions through doorto-door visits with beneficiaries in selected slums. ${ }^{31}{ }^{32}$ Using mobile phones they also help ensure referrals have occurred and work to reduce delays in accessing EmOC services in emergencies thereby helps to ensure continuity of maternal and child health services. ${ }^{33}$ Every SS has a catchment area of around 200 households. She visits each of this household every month and immediately notifies the respective $S K$ of any pregnancies. $S K$ s are the direct supervisor of $S S$ who provide home-based ANC services to the pregnant women and visit each household every 3 months. Moreover, through Manoshi programme
BRAC has established several delivery centres in the slums where a separate cadre called urban birth attendants are employed.

\section{Data collection}

A pretested semistructured questionnaire (online supplemental file 1) was used to collect the information through face-to-face interviews of the study participants. Data collection was accomplished by female research assistants, recruited based on educational qualification and previous experience of administering maternal and child health surveys. The research assistants were trained extensively on the goal and objectives of the study and every aspect of the questionnaire before the data collection.

\section{Measures}

\section{Outcome measures}

The use of mobile phones (yes/no) was defined as having ever used a mobile for purposes such as telephone calls, texting, mobile money transfer or mobile internet. Mobile phone use for maternal and child healthcare purposes was defined as usage of mobile phones for accessing maternal and child health-related care by calling a doctor/nurse/ other health worker, texting a doctor/nurse/other health worker, paying for healthcare with mobile money or looking up healthcare information on the internet over the last antenatal or postnatal period.

\section{Explanatory variables}

Explanatory factors considered in this study were the participants' age (binned into groups of 15-19, 20-24, 25-29, 30-34 and 35+ years), religion (Muslim/others), literacy (yes/no), level of education (no education, completed grades $1-4,5-9$ and 10 or more), involvement in income earning (yes/no) and ownership of mobile phone (yes/ no). The study also considered their husband's age $(<25$, 25-29, 30-34, 35-39, 40+ years), literacy (yes/no), level of education (no education, completed grades 1-4, 5-9 and 10 or more) and occupation (business, labourers, regular job and other). Moreover, household size $(\leq 4 />4)$, type of family (nuclear/extended), sex household head (male/ female), family income in US\$ $(<120,120-239,240-359$, $360+$ ) and household wealth status (lowest, low, middle, high, highest) were considered.

Literacy was defined as the ability to read and write a letter. Total family income of the participants was collected in Bangladeshi taka and converted to US \$ equivalent using https://www.xe.com/. Household wealth index was constructed based on factor analysis ${ }^{34} 35$ of key socioeconomic variables such as types of wall, floor and roof of the house; ownership of a radio, television, computer, bicycle, mobile phone/telephone, refrigerator, wardrobe, table, chair, watch/clock, bed, sewing machine, bicycle, motor vehicle, livestock; and access to solar power and electricity. We used all variables related to assets and ownership to calculate the wealth index and all of them were included in the final factor scores. 


\section{Statistical analysis}

Exploratory data analysis techniques were used to describe the characteristics of the study participants. The Chi square test was performed to compare the use of mobile phones for maternal and child healthcare within different categories of a variable with a $5 \%$ level of significance. The binary logistic regression model was used to determine the association between mobile phone use for maternal and child healthcare and associated factors. Notably, there could be a cluster to cluster variation in the outcome of interest due to the nature of the study design. Therefore, we employed the binary logistic regression model in the generalised estimating equation framework to capture the variation due to cluster random sampling. ${ }^{36}$ In this case, we considered an exchangeable correlation structure among clusters. We determined the crude association of mobile phone use and each covariate and reported the crude OR. The final model was selected by the strategy followed by Agresti ${ }^{37}$ in building the logistic regression. That is, the final model includes only the variables having $\mathrm{p}<0.25$ in the unadjusted analysis. ${ }^{38}$ The adjusted OR (aOR) was reported with 95\% CIs. All analyses were performed using the statistical software Stata (V.13.0).

\section{Patient and public involvement}

Neither patients nor the public were involved in the design or conduct of this study. Participants also did not contribute to the writing or editing of this manuscript. Informed written consent was sought from each participant before the interview.

\section{RESULTS}

\section{Background characteristics}

A total of 800 women who gave birth over the previous 12 months took part in the study. Nearly $35 \%$ were between 20 and 24 years and $30 \%$ between 25 and 29 years (table 1). Most of the participants were Muslim (98.5\%), literate $(64.0 \%)$, with primary or secondary education completed $(52.3 \%)$ and were not involved in incomeearning activities (86.4\%). Their husbands were also mostly literate $(64.9 \%)$, with primary or secondary education completed $(51.5 \%)$ and most worked as labourers $(38.6 \%)$. More than $80 \%$ of the participants lived within a nuclear family and about half of the participants had a family income of US\$120-239 per month.

\section{Usage of mobile phone for maternal and child healthcare services}

More than half of the participants had their own mobile phone, and almost all the participants had access to mobile phone within their family, usually used for making telephone calls. Overall, $73.8 \%$ of the participants reported that they have used mobile phones for seeking maternal and child healthcare. Approximately $73.5 \%$ of the participants reported using them for calling a doctor, nurse or other health worker (table 2). Mobile phone use
Table 1 Background characteristics of the study participants $(\mathrm{N}=800)$

\begin{tabular}{|c|c|c|}
\hline Characteristics & $\mathbf{n}$ & $\%$ \\
\hline \multicolumn{3}{|c|}{ Characteristics of participants } \\
\hline \multicolumn{3}{|c|}{ Age (years) } \\
\hline $15-19$ & 118 & 14.8 \\
\hline $20-24$ & 277 & 34.6 \\
\hline $25-29$ & 233 & 29.1 \\
\hline $30-34$ & 117 & 14.6 \\
\hline $35+$ & 55 & 6.9 \\
\hline \multicolumn{3}{|l|}{ Religion } \\
\hline Muslim & 788 & 98.5 \\
\hline Others* & 12 & 1.5 \\
\hline \multicolumn{3}{|c|}{ Literacy (can read and write) } \\
\hline Yes & 512 & 64.0 \\
\hline No & 288 & 36.0 \\
\hline \multicolumn{3}{|l|}{ Level of education } \\
\hline No education & 118 & 14.8 \\
\hline Primary incomplete† & 169 & 21.1 \\
\hline $\begin{array}{l}\text { Primary or secondary } \\
\text { incompleteł }\end{array}$ & 418 & 52.3 \\
\hline Secondary or higher§ & 95 & 11.9 \\
\hline \multicolumn{3}{|c|}{ Involved in income earning } \\
\hline Yes & 109 & 13.6 \\
\hline No & 691 & 86.4 \\
\hline
\end{tabular}

Characteristics of their husbands

\begin{tabular}{|c|c|c|}
\hline \multicolumn{3}{|l|}{ Age (years) } \\
\hline$<25$ & 79 & 9.9 \\
\hline $25-29$ & 261 & 32.6 \\
\hline 30-34 & 185 & 23.1 \\
\hline $35-39$ & 206 & 25.8 \\
\hline $40+$ & 69 & 8.6 \\
\hline \multicolumn{3}{|c|}{ Literacy (can read and write) } \\
\hline Yes & 519 & 64.9 \\
\hline No & 281 & 35.1 \\
\hline \multicolumn{3}{|l|}{ Level of education } \\
\hline No education & 185 & 23.1 \\
\hline Primary incomplete† & 114 & 14.3 \\
\hline $\begin{array}{l}\text { Primary or secondary } \\
\text { incompleteł }\end{array}$ & 412 & 51.5 \\
\hline Secondary or higher§ & 89 & 11.1 \\
\hline \multicolumn{3}{|l|}{ Current occupation } \\
\hline Business & 210 & 26.3 \\
\hline Labourer & 309 & 38.6 \\
\hline Regular job & 261 & 32.6 \\
\hline Others & 20 & 2.5 \\
\hline
\end{tabular}

Continued 


\begin{tabular}{|c|c|c|}
\hline Characteristics & $\mathbf{n}$ & $\%$ \\
\hline$\leq 4$ & 496 & 62.0 \\
\hline$>4$ & 304 & 38.0 \\
\hline \multicolumn{3}{|l|}{ Type of family } \\
\hline Nuclear & 643 & 80.4 \\
\hline Extended & 157 & 19.6 \\
\hline \multicolumn{3}{|c|}{ Sex of household head } \\
\hline Male & 774 & 96.8 \\
\hline Female & 26 & 3.2 \\
\hline \multicolumn{3}{|c|}{ Family income per month (US\$) } \\
\hline$<120$ & 90 & 11.3 \\
\hline 120-239 & 432 & 54.0 \\
\hline 240-359 & 163 & 20.4 \\
\hline $360+$ & 115 & 14.4 \\
\hline \multicolumn{3}{|l|}{ Wealth quintileף } \\
\hline Lowest & 161 & 20.1 \\
\hline Low & 170 & 21.3 \\
\hline Middle & 149 & 18.6 \\
\hline High & 162 & 20.3 \\
\hline Highest & 158 & 19.8 \\
\hline
\end{tabular}

${ }^{*}$ Hinduism, Christian, Buddhism.

†Primary incomplete $=$ completed grades 1-4.

‡Primary or secondary incomplete=completed grades 5-9.

$\S$ Secondary or higher=completed grade 10 or higher.

१Household wealth index was constructed using factor analysis of

key socioeconomic variables.

for RMNCH was higher among highly educated participants, those belonging to a female-headed household, whose husbands had regular jobs and were more highly educated, whose family income was relatively higher and who owned mobile phones (table 3).

\section{Factors associated with mobile phone usage}

In the unadjusted analyses, participants' age, literacy, education, involvement in income earning, husbands' age, literacy, education and occupation, type of family, sex of household head, level of income, household wealth status and ownership of mobile phones were found to be moderately to highly significantly correlated to the usage of mobile phones (table 3). After adjusting for potential covariates in a multiple logistic regression model, participants' age, husband's occupation, sex of household head, ownership of a mobile phone and household wealth status remained as significant factors for usage of mobile phones, at $5 \%$ level of significance.

From the adjusted model, it was found that participants aged 20-24 years had 52\% higher odds (aOR: 1.52, 95\% CI: 1.11 to 2.08 ) and 25-29 years had 52\% higher odds (aOR: $1.52,95 \%$ CI: 1.01 to 2.27) of using a mobile phone for maternal and child healthcare compared with
Table 2 Mobile phone ownership and use among the study participants $(\mathrm{N}=800)$

\begin{tabular}{|c|c|c|}
\hline Characteristics & $\mathbf{n}$ & $\%$ \\
\hline $\begin{array}{l}\text { Women owner of mobile } \\
\text { phone }\end{array}$ & 427 & 53.4 \\
\hline $\begin{array}{l}\text { Access to mobile phone } \\
\text { within family }\end{array}$ & 777 & 97.1 \\
\hline \multicolumn{3}{|c|}{ Prior experience using mobile phones for: } \\
\hline Telephone calls & 758 & 97.6 \\
\hline Text message & 72 & 9.3 \\
\hline $\begin{array}{l}\text { Mobile money transfer } \\
\text { (eg, bKash) }\end{array}$ & 35 & 4.5 \\
\hline Using mobile internet & 70 & 9.0 \\
\hline Emailing & 8 & 1.0 \\
\hline $\begin{array}{l}\text { Women using mobile for } \\
\text { maternal and child health } \\
\text { purpose }\end{array}$ & 590 & 73.8 \\
\hline $\begin{array}{l}\text { a. Calling doctor/nurse/ } \\
\text { other health worker }\end{array}$ & 588 & 73.5 \\
\hline $\begin{array}{l}\text { b. Texting doctor/nurse/ } \\
\text { other health worker }\end{array}$ & 9 & 1.1 \\
\hline $\begin{array}{l}\text { c. Paying for healthcare } \\
\text { with mobile money }\end{array}$ & 6 & 0.8 \\
\hline $\begin{array}{l}\text { d. Looking up healthcare } \\
\text { info on internet }\end{array}$ & 7 & 0.9 \\
\hline
\end{tabular}

(a-d): multiresponse.

those aged 15-19 years. Participants involved in incomeearning activities had nearly twice odds of using a mobile phone than those of not involved in earning activities (aOR: $1.97,95 \%$ CI: 0.84 to 4.60 ). The participants that belonged to female-headed households had $85 \%$ higher odds (aOR: 1.85, 95\% CI: 1.14 to 3.02) and those who were owners of mobile phones had $30 \%$ higher odds (aOR: $1.30,95 \%$ CI: 1.03 to 1.66 ) of using a mobile phone for maternal and child healthcare. Participants with husbands in regular job had $46 \%$ higher odds of using a mobile phone compared with the participants whose husbands were labourers (aOR: 1.46, 95\% CI: 1.08 to 1.97). Also, participants who were from households of the highest wealth quintile had nearly five times odds (aOR: $4.38,95 \%$ CI: 1.27 to 15.04 ) of using a mobile phone for maternal and child healthcare compared with those from the lowest quintile (table 3).

\section{DISCUSSION}

This study investigated mobile phone usage for seeking maternal and child healthcare services and its determinants among mothers who have recently given birth, living in urban slums of Bangladesh where BRAC has been implementing its Manoshi intervention. Our findings revealed that access to a mobile phone by the mothers is near to universal (97.1\%), and among them $73.8 \%$ 
Table 3 Association of maternal, husband and household characteristics with mobile phone usage for RMNCH purposes among the study participants $(\mathrm{N}=800)$

\begin{tabular}{|c|c|c|c|c|c|c|c|c|}
\hline \multirow[b]{3}{*}{ Characteristics } & \multicolumn{8}{|c|}{ Mobile phone usage for RMNCH purposes } \\
\hline & \multicolumn{2}{|c|}{ Yes } & \multicolumn{3}{|c|}{ Crude } & \multicolumn{3}{|c|}{ Adjusted } \\
\hline & $\%$ & $P$ value & OR & $95 \% \mathrm{Cl}$ & $\begin{array}{l}P \\
\text { value }\end{array}$ & OR & $95 \% \mathrm{Cl}$ & $\begin{array}{l}P \\
\text { value }\end{array}$ \\
\hline \multicolumn{9}{|l|}{ Women characteristics } \\
\hline \multicolumn{9}{|l|}{ Age (years) } \\
\hline $15-19$ & 66.1 & 0.126 & Ref & & & & & \\
\hline $20-24$ & 76.2 & & 1.68 & 1.15 to 2.46 & 0.007 & 1.52 & 1.11 to 2.08 & 0.008 \\
\hline $25-29$ & 75.1 & & 1.84 & 1.13 to 3.01 & 0.014 & 1.52 & 1.01 to 2.27 & 0.042 \\
\hline 30-34 & 76.9 & & 1.85 & 0.76 to 4.52 & 0.174 & 1.41 & 0.69 to 2.88 & 0.345 \\
\hline $35+$ & 65.5 & & 1.27 & 0.58 to 2.77 & 0.554 & 1.00 & 0.47 to 2.15 & 0.998 \\
\hline \multicolumn{9}{|l|}{ Religion } \\
\hline Others* & 83.3 & 0.447 & Ref & & & & & \\
\hline Muslim & 73.6 & & 1.12 & 0.59 to 2.13 & 0.725 & Droppe & om final model & \\
\hline \multicolumn{9}{|l|}{ Literacy (can read and write) } \\
\hline No & 70.8 & 0.160 & Ref & & & & & \\
\hline Yes & 75.4 & & 1.36 & 0.84 to 2.20 & 0.218 & 0.96 & 0.59 to 1.56 & 0.861 \\
\hline \multicolumn{9}{|l|}{ Level of education } \\
\hline No education & 72.4 & 0.001 & Ref & & & & & \\
\hline Primary incomplete† & 65.1 & & 0.81 & 0.46 to 1.42 & 0.461 & 0.76 & 0.45 to 1.28 & 0.305 \\
\hline Primary or secondary incompleteł & 74.9 & & 1.16 & 0.62 to 2.18 & 0.645 & 0.99 & 0.49 to 2.01 & 0.979 \\
\hline Secondary or higher§ & 91.2 & & 3.56 & 1.33 to 9.52 & 0.011 & 2.22 & 0.66 to 7.51 & 0.200 \\
\hline \multicolumn{9}{|l|}{ Involved in income earning } \\
\hline No & 72.8 & 0.121 & Ref & & & & & \\
\hline Yes & 79.8 & & 2.11 & 0.89 to 5.03 & 0.091 & 1.97 & 0.84 to 4.60 & 0.118 \\
\hline \multicolumn{9}{|l|}{ Husband characteristics } \\
\hline \multicolumn{9}{|l|}{ Age (years) } \\
\hline$<25$ & 73.4 & 0.552 & Ref & & & & & \\
\hline $25-29$ & 72.4 & & 1.28 & 0.92 to 1.77 & 0.137 & 1.17 & 0.78 to 1.76 & 0.444 \\
\hline $30-34$ & 75.7 & & 1.38 & 0.94 to 2.05 & 0.103 & 1.12 & 0.64 to 1.94 & 0.694 \\
\hline $35-39$ & 76.2 & & 1.57 & 0.88 to 2.81 & 0.124 & 1.27 & 0.70 to 2.28 & 0.434 \\
\hline $40+$ & 66.7 & & 1.22 & 0.59 to 2.53 & 0.584 & 1.40 & 0.60 to 3.28 & 0.442 \\
\hline \multicolumn{9}{|l|}{ Literacy (can read and write) } \\
\hline No & 69.8 & 0.059 & & & & & & \\
\hline Yes & 75.9 & & 1.39 & 0.89 to 2.16 & 0.148 & 1.10 & 0.57 to 2.14 & 0.771 \\
\hline \multicolumn{9}{|l|}{ Level of education } \\
\hline No education & 70.3 & 0.069 & & & & & & \\
\hline Primary incomplete† & 68.4 & & 1.21 & 0.74 to 1.98 & 0.450 & 1.05 & 0.57 to 1.91 & 0.881 \\
\hline Primary or secondary incompleteł & 74.8 & & 1.32 & 0.87 to 2.00 & 0.197 & 0.90 & 0.44 to 1.83 & 0.764 \\
\hline Secondary or higher§ & 83.2 & & 2.06 & 1.11 to 3.83 & 0.022 & 0.77 & 0.42 to 1.42 & 0.407 \\
\hline \multicolumn{9}{|l|}{ Occupation } \\
\hline Labourer & 51.0 & 0.000 & & & & & & \\
\hline Business & 74.8 & & 1.48 & 0.91 to 2.42 & 0.116 & 1.12 & 0.73 to 1.73 & 0.610 \\
\hline Regular job & 81.2 & & 1.68 & 1.36 to 2.09 & 0.000 & 1.46 & 1.08 to 1.97 & 0.014 \\
\hline Others & 95.0 & & 3.16 & 1.11 to 8.98 & 0.031 & 1.64 & 0.57 to 4.76 & 0.361 \\
\hline
\end{tabular}


Table 3 Continued

\begin{tabular}{|c|c|c|c|c|c|c|c|c|}
\hline \multirow[b]{3}{*}{ Characteristics } & \multicolumn{8}{|c|}{ Mobile phone usage for RMNCH purposes } \\
\hline & \multicolumn{2}{|l|}{ Yes } & \multicolumn{3}{|c|}{ Crude } & \multicolumn{3}{|c|}{ Adjusted } \\
\hline & $\%$ & $P$ value & OR & $95 \% \mathrm{Cl}$ & $\begin{array}{l}P \\
\text { value }\end{array}$ & OR & $95 \% \mathrm{Cl}$ & $\begin{array}{l}P \\
\text { value }\end{array}$ \\
\hline \multicolumn{9}{|c|}{ Household characteristics } \\
\hline \multicolumn{9}{|c|}{ Household size } \\
\hline$\leq 4$ & 73.4 & 0.766 & & & & & & \\
\hline$>4$ & 74.3 & & 1.01 & 0.70 to 1.45 & 0.977 & Dropp & m final model & \\
\hline \multicolumn{9}{|l|}{ Type of family } \\
\hline Nuclear & 72.5 & 0.097 & & & & & & \\
\hline Extended & 79.0 & & 1.26 & 1.01 to 1.58 & 0.037 & 1.08 & 0.78 to 1.50 & 0.627 \\
\hline \multicolumn{9}{|l|}{ Household head } \\
\hline Male & 73.1 & 0.029 & & & & & & \\
\hline Female & 92.3 & & 2.05 & 1.11 to 3.79 & 0.021 & 1.85 & 1.14 to 3.02 & 0.013 \\
\hline \multicolumn{9}{|c|}{ Income per month (US\$) } \\
\hline$<120$ & 66.7 & 0.011 & & & & & & \\
\hline 120-239 & 70.8 & & 1.43 & 0.80 to 2.57 & 0.230 & 1.09 & 0.72 to 1.65 & 0.678 \\
\hline 240-359 & 81.6 & & 1.83 & 1.09 to 3.07 & 0.022 & 1.12 & 0.68 to 1.83 & 0.655 \\
\hline $360+$ & 79.1 & & 1.65 & 0.99 to 2.74 & 0.052 & 0.83 & 0.48 to 1.43 & 0.501 \\
\hline \multicolumn{9}{|l|}{ Wealth quintile } \\
\hline Lowest & 73.9 & 0.075 & & & & & & \\
\hline Low & 77.7 & & 1.42 & 1.06 to 1.90 & 0.019 & 1.33 & 0.96 to 1.83 & 0.084 \\
\hline Middle & 73.8 & & 1.67 & 1.17 to 2.38 & 0.004 & 1.51 & 1.07 to 2.14 & 0.019 \\
\hline High & 65.6 & & 1.53 & 1.05 to 2.22 & 0.025 & 1.33 & 0.85 to 2.08 & 0.208 \\
\hline Highest & 77.8 & & 5.06 & 2.09 to 12.24 & 0.000 & 4.38 & 1.27 to 15.04 & 0.019 \\
\hline \multicolumn{9}{|c|}{ Women's ownership of mobile phone } \\
\hline No & 68.9 & 0.004 & & & & & & \\
\hline Yes & 78.0 & & 1.58 & 1.07 to 2.32 & 0.021 & 1.30 & 1.03 to 1.66 & 0.031 \\
\hline
\end{tabular}

*Hinduism, Christian, Buddhism.

†Primary incomplete=completed grades $1-4$.

‡Primary or secondary incomplete $=$ completed grades 5-9.

$\S$ Secondary or higher $=$ completed grade 10 or higher.

$\mathrm{RMNCH}$, reproductive, maternal, newborn and child health.

used a mobile phone for RMNCH purposes. This finding suggests dramatic improvements over the last decade in reach, availability and affordability of mobile phones in Bangladesh. ${ }^{39}$ This study also found that after adjusting all the potential covariates in the multiple logistic regression model, some sociodemographic characteristics such as a women's age (20-24 and 25-29 years compared with 15-16 years), their husband's occupation (who are in regular jobs compared with labour), the household head (female-headed households), wealth quintile (middle and highest compared with lowest) and participants' ownership of a mobile phone remained as significant determinants for usage of mobile phone for RMNCH by recently delivered mothers in urban slums.

We found a relatively high prevalence $(73.8 \%)$ of mobile phone usage among recently delivered women in slum areas for seeking any maternal and child healthcare services during their most recent pregnancy, childbirth or postnatal period. This prevalence is substantially higher compared with other studies carried out in Bangladesh. ${ }^{22}{ }^{40}$ For example, Bishwajit $e t a l^{22}$ analysed data from the most recent urban health survey (2013) and reported that only $7.4 \%$ women had used a mobile phone for childbirth or delivery-care services in City Corporation slum areas of Bangladesh. In another study, Tang et $a l^{40}$ reported using 2014 data that $28.4 \%$ women used mobile phones to get health services in Bangladesh. Several factors might have contributed to the higher mobile phone usage among our study participants. First, other studies usually explored the usage of mobile phone for only one or two components of the whole continuum of maternal and child healthcare (antenatal, delivery, postnatal and child 
health) whereas we considered any maternal and child healthcare services. Second, the participating mothers are project participants of the Manoshi intervention ${ }^{11}$ where there is an established referral system and project participants often are assisted to effectively communicate with healthcare providers using mobile phones. Finally, the use of mobile phones has dramatically increased since these analyses were conducted using 2013 and 2014 data. However, it is also critical to note that these mobile phone use patterns were in the absence of any formal digital health/mHealth services offered by either Manoshi or other government health programmes. In fact, Bangladesh is at the very early stage of mHealth initiative. The only mHealth services available are telemedicine, prescription and referral. ${ }^{41}$ All slum dwellers we sampled also will have their health workers' phone number available to help them with these services.

Age was identified as a significant factor for using a mobile phone for RMNCH in this study, with women between 20 and 29 years having higher odds of using their phone compared with those aged 15-19 years. These findings are in line with other studies conducted in Bangladesh ${ }^{22} 40$ and in similar settings. ${ }^{42}$ One potential explanation may be that women of this age group may be more likely to have access to their own device and thus use mobile and other technologies. ${ }^{40}$ Chakraborty et $a t^{43}$ also report that adult mothers are more likely to use maternal and child care services compared with the adolescent mothers.

This study reports that the usage of a mobile phone for accessing RMNCH was significantly higher among women who belonged to female-headed households. This points the importance of decision-making capacity being in the hand of a woman rather than a male gatekeeper in accessing healthcare services promptly. ${ }^{44} 45$

Similar to other findings, ${ }^{40} 46$ we found that women who belonged to higher wealth quintiles had higher odds of using a mobile phone for RMNCH services, though the association was weaker here than in other studies. This finding is suggestive of a role of wealth or financial well-being for having a mobile phone and using that for healthcare-seeking purposes.

Another finding of the current study is that women whose husbands were employed in regular jobs had a higher chance of using a mobile phone for RMNCH services compared with the participants whose husbands were labourers. This is an under-researched factor regarding the issue of mobile usage for healthcare services among women. One possible explanation could be that the level of knowledge and quality of life would be higher among women whose husbands are service holders which enabled them to seek care more promptly using phone. However, one study identified husband's occupation as an important determinant of maternal healthcare use and reported that wives of men who work in business or service are more likely to seek maternal health services from skilled providers compared with wives of farmers. ${ }^{43}$ So, more research is needed to better understand this variable's influence on mobile phone use for maternal and child healthcare services by women.

We found that the use of mobile phones for seeking RMNCH was significantly higher among women who had a mobile phone of their own. Previous studies have highlighted the importance of mobile phone ownership in increasing women's decision-making power, empowerment, social status and access to health resources. ${ }^{47-49}$ LeFevre et $a \tilde{p}^{0}$ carried out a study to investigate the ownership of mobile phones among women and careseeking practices for RMNCH using demographic and health survey data from 15 countries. The study found that mobile phone ownership is associated with increased uptake of RMNCH interventions, and authors concluded that the gender gap in phone ownership should be reduced to accelerate health interventions, notably those which have a digital component.

A key strength of this study is that it focuses squarely on an urban slum population using a multistage cluster random sampling procedure. However, the study is also subject to several limitations. First, the study finding is not generalisable to the entire slum population as the study was carried out in BRAC Manoshi catchment areas. Second, as the data were cross-sectional in nature, temporal relationships between the explanatory variables and mobile usage for maternal and child healthcare should be interpreted with caution. Moreover, the study findings may be subject to self-reporting and recall biases.

\section{CONCLUSION AND POLICY IMPLICATIONS}

This study found that women from slum areas are increasingly using mobile phones for accessing maternal and child healthcare services. These findings point to the possibility of implementing large-scale mHealth interventions in slum settlements in contexts where there are overwhelming maternal and child health issues. This would also be a sustainable solution to the critical shortage of human resources in healthcare sector of the country. However, large-scale longitudinal research is needed to understanding whether the use of mobile phones for RMNCH can improve maternal and child health outcomes. ${ }^{51}$ The study finding is also useful for policymakers and practitioners, as it identifies some of the factors that influence mobile phone usage for accessing maternal and child healthcare. Interventions that increase the factors this study found to be associated with using mobile phones for healthcare may be able to positively impact on access to healthcare for mothers and children who are likely to go without. Paired with other low-cost mHealth innovations, like biometrics and electronic medical records, multidisciplinary interventions may succeed in improving access to care for slum dwellers. As Bangladesh has no clear policy regarding the use of mHealth for maternal and child healthcare, this study can be a starting point from where practitioners and policymakers could look to revise health policy to incorporate mHealth intervention which has also been 
highlighted in the recently inaugurated Digital Health Strategy of Bangladesh. ${ }^{52}$

However, it is important to mention that the present study revealed that phone use was higher among relatively wealthier group indicating a potential digital dividing as has been recently discussed in literature. ${ }^{25}$ Therefore, if not carefully done, investment in mHealth in resourcepoor settings could further health inequality. Policymakers need to consider the democratisation of mobile phone usage and overcoming digital deprivation before investing in promotion of mHealth initiatives. Moreover, policymakers should also consider how relatively older women can be familiarised and engaged in mHealth initiatives.

Several important implementation research questions persist around ensuring the affordability and sustainability of digital health systems in LMICs-ranging from the identification of strong business models to engage the private sector (critical in a pluralistic healthcare framework like Bangladesh), to oversight of quality and assurance of accountability of providers. Many have raised concerns about the continued marginalisation of population strata that may not have access to phones or airtime, exacerbating a socioeconomic digital divide; research and innovation into bridging these gaps are necessaryto ensure Universal Health Coverage is truly universal, and not simply perpetuating decades of inequity now reinforced by technology.

\section{Author affiliations}

${ }^{1}$ BRAC James P Grant School of Public Health, BRAC University, Dhaka, Bangladesh ${ }^{2}$ Centre for Primary Health Care and Equity, University of New South Wales, Sydney, New South Wales, Australia

${ }^{3}$ Center for Research Policy and Implementation, Biratnagar, Nepal

${ }^{4}$ School of Population and Public Health, University of British Columbia, Vancouver, British Columbia, Canada

${ }^{5}$ Cambridge Science Park, Cambridge, UK

${ }^{6}$ Department of International Health, Johns Hopkins University Bloomberg School of Public Health, Baltimore, Maryland, USA

${ }^{7}$ Laboratory of Viral Zoonotics, University of Cambridge, Cambridge, UK

\section{Twitter Uday Narayan Yadav @UNYadav}

Acknowledgements We acknowledge the role of the relevant staff of the Health Nutrition and Population Programme, BRAC, for initial review of the tools and smooth arrangement of the data collection initiatives.

Contributors SKM and DMLS conceived the study and contributed to the design of the study. SKM carried out the data analysis and participated in the interpretation of the results. SKM, FA, UNY and MBH wrote the first draft of the manuscript. AS, ABL and DMLS commented extensively on the draft of the manuscript to finalise it. All authors read and approved the final version of the manuscript.

Funding We received the funding for conducting the research from the UKaid through Simprints Technology (grant no: UKAD-INN-083).

Competing interests None declared.

Patient consent for publication Not required.

Ethics approval The study protocol was approved by the Ethical Review Committee of the James P Grant School of Public Health, BRAC University (ref: 95), and the guidelines of the Declaration of Helsinki were followed in every stage of the study. All participants gave voluntary and informed written consent prior to the interviews. Confidentiality and anonymity were strictly maintained in all stages.

Provenance and peer review Not commissioned; externally peer reviewed.
Data availability statement The data are available from the corresponding author upon reasonable request.

Supplemental material This content has been supplied by the author(s). It has not been vetted by BMJ Publishing Group Limited (BMJ) and may not have been peer-reviewed. Any opinions or recommendations discussed are solely those of the author(s) and are not endorsed by BMJ. BMJ disclaims all liability and responsibility arising from any reliance placed on the content. Where the content includes any translated material, BMJ does not warrant the accuracy and reliability of the translations (including but not limited to local regulations, clinical guidelines, terminology, drug names and drug dosages), and is not responsible for any error and/or omissions arising from translation and adaptation or otherwise.

Open access This is an open access article distributed in accordance with the Creative Commons Attribution Non Commercial (CC BY-NC 4.0) license, which permits others to distribute, remix, adapt, build upon this work non-commercially, and license their derivative works on different terms, provided the original work is properly cited, appropriate credit is given, any changes made indicated, and the use is non-commercial. See: http://creativecommons.org/licenses/by-nc/4.0/.

\section{ORCID iDs}

Sabuj Kanti Mistry http://orcid.org/0000-0001-6100-6076

Uday Narayan Yadav http://orcid.org/0000-0002-6626-1604

Md Belal Hossain http://orcid.org/0000-0003-4603-863X

\section{REFERENCES}

1 Chowdhury AMR, Bhuiya A, Chowdhury ME, et al. The Bangladesh paradox: exceptional health achievement despite economic poverty. Lancet 2013;382:1734-45.

2 Mahmud W, Asadullah MN, Savoia A. Bangladesh's achievements in social development indicators: explaining the puzzle. Economic and Political Weekly 2013:26-8.

3 El Arifeen S, Hill K, Ahsan KZ, et al. Maternal mortality in Bangladesh: a countdown to 2015 country case study. Lancet 2014;384:1366-74.

4 Koblinsky M, Anwar I, Mridha MK, et al. Reducing maternal mortality and improving maternal health: Bangladesh and mdg 5. $\mathrm{J}$ Health Popul Nutr 2008;26:280.

5 National Institute of Population Research and Training, International centre for diarrhoeal disease research $B$, measure evaluation. Bangladesh maternal mortality and health care survey 2016: preliminary report Dhaka, Bangladesh 2017.

6 National Institute of Population Research and Training (NIPORT), Mitra and Associates, ICF International. Bangladesh demographic and health survey 2014. Dhaka, Bangladesh, and Rockville, Maryland, USA: NIPORT, Mitra and Associates, and ICF International, 2016.

7 National Institute of population research and training (NIPORT), measure evaluation, International centre for diarrhoeal disease research B. Bangladesh urban health survey 2013: preliminary results Dhaka, Bangladesh 2013.

8 Ahmed I. Building resilience of urban slums in Dhaka, Bangladesh. Procedia Soc Behav Sci 2016;218:202-13.

9 Mberu BU, Haregu TN, Kyobutungi C, et al. Health and health-related indicators in slum, rural, and urban communities: a comparative analysis. Glob Health Action 2016;9:33163.

10 Sarker BK, Mridha MK, Dasgupta SK. The effect of Behavior Change Communication (BCC) interventions on maternal neonatal and child health $(\mathrm{MNCH})$ knowledge in urban slums of Bangladesh [working paper]. Manoshi Working Paper 2012;17.

11 Choudhury N, Moran AC, Alam MA, et al. Beliefs and practices during pregnancy and childbirth in urban slums of Dhaka, Bangladesh. BMC Public Health 2012;12:791.

12 de Bernis L, Kinney MV, Stones W, et al. Stillbirths: ending preventable deaths by 2030. Lancet 2016;387:703-16.

13 Yaya S, Bishwajit G, Ekholuenetale M. Factors associated with the utilization of institutional delivery services in Bangladesh. PLoS One 2017;12:e0171573.

14 Ahmed SM, Hossain MA, Rajachowdhury AM, et al. The health workforce crisis in Bangladesh: shortage, inappropriate skill-mix and inequitable distribution. Hum Resour Health 2011;9:3.

15 Afsana K, Grant JP, Evans J. Crisis of health workforce in Bangladesh: a non-government organization's experience in deploying community health workers in primary health care. Perspect Public Health 2014;134:253-4.

16 World Health Organization. Health workforce requirements for universal health coverage and the sustainable development goals. 
(human resources for health observer, 17). Geneva: World Health Organization, 2016.

17 Khatun F, Hanifi SMA, lqbal M, et al. Prospects of mHealth services in Bangladesh: recent evidence from Chakaria. PLoS One 2014;9:e111413.

18 El-Saharty S, Sparkes SP, Barroy H. The path to universal health coverage in Bangladesh: bridging the gap of human resources for health. Washington, DC: The World Bank, 2015.

19 Labrique A, Vasudevan L, Mehl G, et al. Digital health and health systems of the future. Global Health: Science and Practice 2018;6:S1-4.

20 Dhaliwal I, Hanna R. The devil is in the details: the successes and limitations of bureaucratic reform in India. J Dev Econ 2017;124:1-21.

21 Zarei M. Portable biosensing devices for point-of-care diagnostics: recent developments and applications. TrAC Trends in Analytical Chemistry 2017;91:26-41.

22 Bishwajit G, Hoque MR, Yaya S. Disparities in the use of mobile phone for seeking childbirth services among women in the urban areas: Bangladesh urban health survey. BMC Med Inform Decis Mak 2017; 17:182.

23 Banerjee A, Bhawalkar JS, Jadhav SL, et al. Access to health services among slum dwellers in an industrial township and surrounding rural areas: a rapid epidemiological assessment. J Family Med Prim Care 2012;1:20.

24 Anstey Watkins JOT, Goudge J, Gómez-Olivé FX, et al. Mobile phone use among patients and health workers to enhance primary healthcare: a qualitative study in rural South Africa. Soc Sci Med 2018;198:139-47.

25 Rotondi V, Kashyap R, Pesando LM, et al. Leveraging mobile phones to attain sustainable development. Proc Natl Acad Sci U S A 2020;117:13413-20.

26 Mair F, Whitten P. Systematic review of studies of patient satisfaction with telemedicine. BMJ 2000;320:1517-20.

27 Feroz A, Perveen S, Aftab W. Role of mHealth applications for improving antenatal and postnatal care in low and middle income countries: a systematic review. BMC Health Serv Res 2017;17:704.

28 World Health Organization. Who guideline: recommendations on digital interventions for health system strengthening. Geneva: WHO, 2019.

29 Agresti A. An introduction to categorical data analysis. Hoboken: John Wiley \& Sons, 2018.

30 StataCorp LP. Stata power and sample-size reference manual. Texas: A Stata Press Publication StataCorp LP, 2013: 12. 2018.

31 Ahmed SM, Hossain A, Khan MA, et al. Using formative research to develop $\mathrm{MNCH}$ programme in urban slums in Bangladesh: experiences from MANOSHI, brac. BMC Public Health 2010;10:663.

32 Sarker BK, Ahmed S, Islam N, et al. Cost of behavior change communication channels of Manoshi -A maternal, neonatal and child health $(\mathrm{MNCH})$ program in urban slums of Dhaka, Bangladesh. Cost Eff Resour Alloc 2013;11:28.

33 Nahar S, Banu M, Nasreen HE. Women-focused development intervention reduces delays in accessing emergency obstetric care in urban slums in Bangladesh: a cross-sectional study. BMC Pregnancy Childbirth 2011;11:1-10.
34 Johnson R, Wichern D. Multivariate analysis. 6th edition. Wiley Online Library, 2007.

35 Rutstein S. Steps to constructing the new DHS wealth index. Rockville, MD: ICF International, 2015.

36 Hanley JA, Negassa A, Edwardes MDdeB, MDd E, et al. Statistical analysis of correlated data using generalized estimating equations: an orientation. Am J Epidemiol 2003;157:364-75.

37 Agresti A. Building and applying logistic regression models. Categorical Data Analysis 2007:211-66.

38 Liang K-YEE, Zeger SL. Longitudinal data analysis using generalized linear models. Biometrika 1986;73:13-22.

39 Tran MC, Labrique AB, Mehra S, et al. Analyzing the mobile "digital divide": changing determinants of household phone ownership over time in rural bangladesh. JMIR Mhealth Uhealth 2015;3:e24.

40 Tang S, Ghose B, Hoque MR, et al. Women using mobile phones for health communication are more likely to use prenatal and postnatal services in Bangladesh: cross-sectional study. JMIR Mhealth Uhealth 2019;7:e10645

41 Ahmed T, Lucas $\mathrm{H}$, Khan AS, et al. eHealth and mHealth initiatives in Bangladesh: a scoping study. BMC Health Serv Res 2014;14:1-9.

42 Kamala A. Women's age and use of maternal health services in rural Nepal. Indian Journal Of Maternal And Child Health 2013;15:1-9.

43 Chakraborty N, Islam MA, Chowdhury Rl, et al. Determinants of the use of maternal health services in rural Bangladesh. Health Promot Int 2003;18:327-37.

44 Doctor HV. Does living in a female-headed household lower child mortality? the case of rural Nigeria. Rural Remote Health 2011;11:1635.

45 Ganle JK, Obeng B, Segbefia AY, et al. How intra-familial decisionmaking affects women's access to, and use of maternal healthcare services in Ghana: a qualitative study. BMC Pregnancy Childbirth 2015;15:173.

46 Huq L, Koehlmoos TL, Azmi AJ. Use of mobile phone: communication barriers in maternal and neonatal emergencies in rural Bangladesh. International Journal of Sociology and Anthropology 2012;4:226-37.

47 Jennings L, Gagliardi L. Influence of mHealth interventions on gender relations in developing countries: a systematic literature review. Int $J$ Equity Health 2013;12:85.

48 RowntreeO. The mobile gender gap report 2018. London, UK: GSMA connected women, 2018.

49 Murphy LL, Priebe AE. "My co-wife can borrow my mobile phone!" Gendered Geographies of Cell Phone Usage and Significance for Rural Kenyans. Gender, Technology and Development 2011;15:1-23.

50 LeFevre AE, Shah N, Bashingwa JJH, et al. Does women's mobile phone ownership matter for health? Evidence from 15 countries. BMJ Glob Health 2020;5:e002524.

51 Noordam AC, Kuepper BM, Stekelenburg J, et al. Improvement of maternal health services through the use of mobile phones. Trop Med Int Health 2011;16:622-6.

52 World Health Organization. Bangladesh initiates digital health strategy, 2019. Available: https://www.who.int/bangladesh/news/ detail/17-10-2019-bangladesh-initiates-digital-health-strategy\#: : text=Ministry\%20of\%20Health\%20and\%20Family,and\% 20affordability\%20of\%20health\%20services 